\title{
Sex differences in the impact of the Mediterranean diet on cardiovascular risk profile
}

\author{
Alexandra Bédard ${ }^{1,2}$, Mélissa Riverin ${ }^{1,2}$, Sylvie Dodin ${ }^{1,3}$, Louise Corneau ${ }^{1}$ and Simone Lemieux ${ }^{1,2 *}$ \\ ${ }^{1}$ Institute of Nutraceuticals and Functional Foods, 2440 Hochelaga Boulevard, Laval University, QC Canada, G1V OA6 \\ ${ }^{2}$ Department of Food Science and Nutrition, Pavillon Paul-Comtois, 2425 rue de l'Agriculture, Laval University, QC, \\ Canada, G1V OA6 \\ ${ }^{3}$ Department of Obstetrics and Gynaecology, Pavillon Ferdinand-Vandry, 1050 Medicine Avenue, Laval University, \\ QC, Canada, G1V OA6
}

(Submitted 18 August 2011 - Final revision received 23 November 2011 - Accepted 23 November 2011 - First published online 6 January 2012)

\begin{abstract}
The traditional Mediterranean diet (MedDiet) is now widely recommended in the prevention of CVD. However, it is not known whether the MedDiet has the same beneficial cardiovascular effects in women and in men. The objective of the present study was to investigate sex-related differences with regard to changes in cardiometabolic variables in response to a 4-week isoenergetic MedDiet. Participants were thirty-eight men and thirty-two premenopausal women aged between 25 and 50 years who had slightly elevated LDL-cholesterol (LDL-C) concentrations $(3.4-4.9 \mathrm{mmol} / \mathrm{l})$ or total cholesterol:HDL-cholesterol ratio $\geq 5 \cdot 0$. A 4 -week run-in period preceded the MedDiet in order to control the inter- and intra-individual variability. Cardiometabolic variables were measured before and after the MedDiet. Total cholesterol, LDL-C, apoB and apoA-1 plasma concentrations as well as diastolic blood pressure decreased $(P<0 \cdot 05)$ in both men and women (respectively, 10, 10, 10, 6 and 5\% for men and 6, 7, 9, 4 and 4\% for women). ApoA-2 concentrations and insulin concentrations $2 \mathrm{~h}$ after the oral administration of $75 \mathrm{~g}$ of glucose demonstrated sex $\times$ time interactions (respectively, $P=0.05$ and $P=0.03$ ) and only men experienced a decrease for these variables (respectively, 8 and 25\%). In conclusion, consuming a MedDiet led to significant changes in plasma lipid profile in both men and women, while only men had significant improvements in insulin homeostasis. These results support the importance of investigating sex-related differences in response to diet in order to perhaps further individualise dietary guidelines in the prevention of CVD and type 2 diabetes.
\end{abstract}

Key words: Mediterranean diet: Sex differences: Lipid profile: Blood pressure: Insulin sensitivity

CVD is still one of the leading causes of mortality in Canada accounting for the death of $28 \%$ of Canadians ${ }^{(1)}$. In order to decrease the rate of CVD, many organisations, such as the Canadian Cardiovascular Society, recommend that the prevention of CVD should always include the adoption of healthy dietary habits. Accordingly, the cardiovascular benefits of the traditional Mediterranean diet (MedDiet) have been widely investigated since the Seven Countries Study has highlighted its cardioprotective effects ${ }^{(2)}$. In fact, beneficial effects of the MedDiet on lipid profile, insulin sensitivity and blood pressure have been demonstrated in the context of both epidemiological and interventional studies ${ }^{(3,4)}$. A systematic review of published studies concluded in a significant effect of the MedDiet on the reduction of CVD rate ${ }^{(5)}$.

Very few studies have investigated sex-related differences in response to diet. Accordingly, some evidence suggests that women could respond differently to diet compared with men due in part to sex hormones ${ }^{(6,7)}$. In fact, the response to alterations in dietary fats and carbohydrates in women appears to be greater for TAG and HDL-cholesterol (HDL-C) concentrations and smaller for LDL-cholesterol (LDL-C) and apoB concentrations than in men ${ }^{(6)}$. However, even if well-controlled studies are essential to isolate sex-related differences in response to diet with a maximum of control over confounding variables, only a few controlled studies have to date assessed sex differences in cardiovascular response to a single or to a few dietary changes in fatty acid or in macronutrient intakes ${ }^{(6,7)}$. More importantly, even if the MedDiet is now widely recommended in the prevention of $\mathrm{CVD}^{(8)}$, no controlled study has yet investigated whether women would respond differently compared with men to the MedDiet despite the fact that most cross-sectional and interventional studies concerning the cardiovascular effects of the MedDiet have been conducted in predominantly male cohorts.

Abbreviations: HDL-C, HDL-cholesterol; LDL-C, LDL-cholesterol; MedDiet, Mediterranean diet; MedScore, Mediterranean score. 
Some epidemiological data support the existence of sex differences in response to the MedDiet since some studies have shown that the consumption of a MedDiet seems to lower CVD risks more in women than in men ${ }^{(9,10)}$. However, results from the National Health and Nutrition Examination Survey III showed that adherence to the MedDiet is positively associated with insulin sensitivity in men younger than 45 years of age but not in premenopausal women ${ }^{(11)}$. The purpose of the present study is to verify for the first time whether changes in cardiometabolic variables differ between men and women in response to an isoenergetic controlled experimental diet based on the traditional MedDiet.

\section{Participants and methods \\ Study population}

Men and premenopausal women, 25-50 years of age, with slightly elevated LDL-C concentrations (between 3.4 and $4.9 \mathrm{mmol} / \mathrm{l})$ or total cholesterol:HDL-C ratio $\geq 5.0$ were recruited from the Quebec City metropolitan area (Canada). Moreover, participants had to have at least one of the four following factors of the metabolic syndrome ${ }^{(12)}$ : (1) waist circumference $>94 \mathrm{~cm}$ in men and $>80 \mathrm{~cm}$ in women ${ }^{(13)}$; (2) TAG $>1.7 \mathrm{mmol} / 1$; (3) fasting glycaemia between 6.1 and $6.9 \mathrm{mmol} / \mathrm{l}$; (4) blood pressure concentrations $\geq 130$ / $85 \mathrm{mmHg}$. In women, premenopausal status was determined by a regular menstrual cycle for the last 3 months and if needed, a follicle-stimulating hormone (FSH) measurement during the early follicular phase confirmed the premenopausal status $(\mathrm{FSH}<20 \mathrm{IU} / 1)$. We decided to compare men with premenopausal women in order to maximise differences due to sex hormones. Men and women included in the study were matched on a group basis for LDL-C, age and BMI. We excluded participants with a significant weight change $(>2.5 \mathrm{~kg})$ in the 3 months before the study, participants who had endocrine disorders, cardiovascular events or type 1 or 2 diabetes and those who used medication that could affect dependent variables under study. Smokers as well as pregnant women and those using systemic hormonal contraceptives were also excluded. A total of seventy-five of the 144 volunteers seen at screening met the inclusion criteria. Of these, four men and one woman dropped out during the run-in period for personal reasons. Thus, thirty-eight men and thirty-two women completed the study. The present study was conducted according to the guidelines laid down in the Declaration of Helsinki. All procedures involving human subjects were approved by the Laval University Research Ethics Committee on human experimentation. Written informed consent was obtained from all subjects. This clinical trial was registered at www.clinicaltrials.gov as NCT01293344.

\section{Study design}

A 4-week run-in period preceded the experimental MedDiet phase in order to control for the inter- and intra-individual variability in dietary intakes. At the beginning of the run-in period, all participants met a registered dietitian who asked and instructed them to comply with healthy eating as recommended by Canada's Food Guide ${ }^{(14)}$. Briefly, Canada's Food Guide is an educational tool which promotes healthy eating for Canadians and which indicates the recommended number of food guide servings per day for each of the four food groups according to the age and sex of individuals. The four food groups are vegetables and fruits, grain products, milk and alternatives, and meat and alternatives. Participants were also instructed to maintain constant their body weight and physical activity participation.

The experimental phase was undertaken as a parallel design in which both men and women were assigned to a 4-week experimental diet formulated to be concordant with the characteristics of the traditional MedDiet ${ }^{(15)}$. All foods and drinks were prepared by food technicians at the Clinical Investigation Unit at the Institute of Nutraceuticals and Functional Foods (Laval University) and were provided to participants according to a $7 \mathrm{~d}$ cyclic menu in order to have an optimal control over energy intake and diet quality. The experimental diet contained key foods of the Mediterranean pyramid ${ }^{(15)}$ (Table 1). Moreover, the nutritional composition of the experimental MedDiet was in concordance with the one found in the traditional MedDiet (Table 2). This menu provided a MUFA:SFA ratio of 2.7 corresponding to the one found in the traditional MedDiet (16). The experimental MedDiet was formulated by using NUTRITION DATA SYSTEM software (version 4.03_31; Nutrition Coordinating Center). Participants were instructed to consume only the foods provided and their entire meals. Vitamin and mineral supplements as well as natural health products were forbidden.

On weekdays, participants came to the Clinical Investigation Unit to consume their noon meal under supervision, at which time they picked up their evening meal and the next day's packaged breakfast. Weekend meals were prepared, packaged and provided at Friday visits. In order to maintain a constant weight during the experimental MedDiet

Table 1. Servings of key foods of the Mediterranean pyramid consumed daily during the experimental Mediterranean diet (MedDiet) phase for a $10460 \mathrm{~kJ} / \mathrm{d}(2500 \mathrm{kcal} / \mathrm{d})$ menu

\begin{tabular}{lc}
\hline Key foods $^{*}$ & MedDiet (servings/d) \\
\hline Olive oil (ml) & $43 \cdot 3$ \\
Whole-grain products & $5 \cdot 7$ \\
Fruits and vegetables & $16 \cdot 1$ \\
Legumes & $0 \cdot 5$ \\
Nuts & $0 \cdot 9$ \\
Cheese and yoghurt & $2 \cdot 0$ \\
Fish & $1 \cdot 3$ \\
Poultry & $0 \cdot 9$ \\
Eggs & $0 \cdot 3$ \\
Sweets & $0 \cdot 3$ \\
Red meat & $0 \cdot 2$ \\
Red wine & $1 \cdot 3$
\end{tabular}

*Extra virgin and virgin olive oils were used. Serving size for whole-grain products $=125 \mathrm{ml}$ (rice, pasta, bulgur, couscous), one bread piece or $30 \mathrm{~g}$ cereal; serving size for fruits and vegetables $=125 \mathrm{ml}$; serving size for legumes $=175 \mathrm{ml}$ and for nuts $=30 \mathrm{~g}$; serving size for fish, poultry and red meat $=75 \mathrm{~g}$; serving size for eggs $=100 \mathrm{~g}$; serving size for dairy products (mostly low-fat cheese and yoghurt) $=50 \mathrm{~g}$ cheese, $175 \mathrm{~g}$ yoghurt and $250 \mathrm{ml}$ milk; Serving size for red wine $=150 \mathrm{ml}$. 
Table 2. Daily nutritional composition of the experimental Mediterranean diet (MedDiet) for a $10460 \mathrm{~kJ} / \mathrm{d}(2500 \mathrm{kcal} / \mathrm{d}) \mathrm{menu}$

\begin{tabular}{lc}
\hline & MedDiet \\
\hline Energy (kJ) & 10460 \\
Carbohydrate (\% of total energy) & $46 \cdot 0$ \\
Fibre (g) & $42 \cdot 3$ \\
Protein (\% of total energy) & $17 \cdot 0$ \\
Fat (\% of total energy) & $32 \cdot 0$ \\
SFA & $6 \cdot 7$ \\
MUFA & $18 \cdot 1$ \\
PUFA & $4 \cdot 7$ \\
Cholesterol (mg) & 289.7 \\
Alcohol (\% of total energy) & $5 \cdot 0$ \\
MUFA:SFA ratio & $2 \cdot 7$ \\
Na (mg) & 3039 \\
\hline
\end{tabular}

phase, the habitual energy intake of each participant was established by averaging the energy requirements estimated by a validated $\mathrm{FFQ}^{(17)}$ administrated at the beginning of the run-in period and energy needs as determined by the Harris-Benedict formula. Body weight was measured on weekdays just before lunch and total energy provided was revised if necessary for minimising body weight fluctuations. In order to evaluate compliance, participants were asked to note on a checklist foods consumed and, if needed, the amount of foods not consumed for each day of the experimental phase. Participants were also instructed to maintain their usual physical activity level. Since some studies have suggested that fluctuations in female hormones influence some metabolic variables ${ }^{(18)}$, women's feeding was shortened or prolonged if needed in order to be able to carry out all tests in the early follicular phase of their menstrual cycle (from the third to the ninth day of the menstrual cycle; mean duration of the feeding period in women, 28.8 (SD 4.3) d).

\section{Dietary intakes}

To determine whether dietary intakes before the experimental MedDiet phase were similar between men and women, a validated quantitative $\mathrm{FFQ}^{(17)}$, containing ninety-one items and thirty-three subquestions, which inquires on food habits during the preceding month was administrated by a registered dietitian just before the experimental MedDiet phase, reflecting dietary habits during the run-in period. A Mediterranean score (MedScore) derived from the FFQ was calculated as described by Goulet and colleagues ${ }^{(19)}$. The MedScore can vary between 0 and 44 points. A MedScore of 44 would imply a food pattern which is perfectly concordant with the traditional MedDiet.

\section{Cardiovascular risk factor measurements}

Biochemical measurements. Blood samples were collected from an antecubital vein into vacutainer tubes containing EDTA after a $12 \mathrm{~h}$ overnight fast. Assessment of the basic lipid profile and of lipoprotein-lipid concentrations were performed according to previously described methods ${ }^{(19)}$. Plasma apoA-1 and apoA-2 concentrations were measured by nephelometry. Glucose and insulin concentrations were measured in a fasting state and $2 \mathrm{~h}$ after an oral administration of $75 \mathrm{~g}$ of glucose. Plasma glucose concentrations were measured with the hexokinase-glucose-6-phosphate dehydrogenase $\operatorname{method}^{(20)}$, whereas plasma insulin concentrations were measured by RIA ${ }^{(21)}$. Insulin sensitivity was assessed by the homeostasis model assessment approach index (1/(fasting glucose $\times$ fasting insulin/22.5)).

Anthropometric and blood pressure measurements. Body weight, height and waist circumference measurements were performed using standardised methods ${ }^{(22)}$. Systolic and diastolic blood pressures were measured on the right arm using an automated blood pressure monitor (BPM 300-BpTRU: Vital Signs Monitor) after a $10 \mathrm{~min}$ rest in the sitting position. Blood pressure was computed as the mean of three readings.

\section{Statistical analyses}

Values are presented as means. Data were collected before and after the experimental MedDiet phase. For variables not normally distributed, a transformation was performed. However, for these variables, raw data are presented in the tables. Student's $t$ test was used to compare macronutrient intakes as well as anthropometric and metabolic variables of men and women before the experimental MedDiet phase. MIXED procedures for repeated measurements were used to evaluate sex, time and sex $\times$ time interaction effects on anthropometric and metabolic variables. In the presence of a significant effect $(P \leq 0 \cdot 05)$, Tukey-Kramer tests were used to determine precisely the location of significant differences.

Although the experimental MedDiet phase aimed at being isoenergetic, both men and women had a small but significant weight loss $(1.2 \mathrm{~kg}$ or $1.3 \%$ of initial body weight in men and $0.5 \mathrm{~kg}$ or $0.7 \%$ in women). Thus, all results concerning metabolic variables are adjusted for weight change during the experimental MedDiet phase. Moreover, if a difference between men and women was observed for a given variable at the beginning of the experimental phase, analyses for this variable were adjusted for baseline value. All analyses were performed with the SAS statistical package version 9.2 (SAS Institute, Inc.) and a $P \leq 0.05$ (two-sided) was considered as significant. We excluded one man from our analyses due to illness, which led to a significant reduction of food intake during several days at the end of the experimental phase. Therefore, thirty-seven men and thirty-two women were included in the analyses.

\section{Results}

At the end of the run-in period, both men and women consumed more than the number of servings per day for all food groups recommended by Canada's Food Guide, except for grain products for which both men and women consumed fewer portions than the recommendations (respectively, for men and women: 5.7 (SD 2.3) and 4.5 (SD 1.4) portions of grain products per day while the recommendation is, respectively, eight portions in men and between six and seven portions in women) (results not shown). 
Before the experimental MedDiet phase (i.e. after the run-in period), women had higher baseline values for HDL-C and apoA-1 and lower baseline values for weight, waist circumference, TAG, apoB, systolic blood pressure, diastolic blood pressure and fasting glucose than men (Table 3). There were also differences between men and women for energy intake $(P<0.0001)$ and for the percentage of energy intake derived from alcohol intake $(P=0 \cdot 02)$, men having higher baseline intakes than women (Table 4 ). There was no significant difference for other macronutrient intakes, for the MUFA:SFA ratio and for the MedScore.

Men decreased their BMI during the 4-week MedDiet $(P<0.0001 ;$ Table 5). After adjustments for weight change during the experimental MedDiet, total cholesterol, LDL-C, apoB, apoA-1 concentrations as well as in diastolic blood pressure decreased in both men and women $(P<0.05)$. Total cholesterol:HDL-C ratio, LDL-C:HDL-C ratio, apoA-2 concentrations and systolic blood pressure decreased but only in men $(P<0.05)$. There was no change for TAG and HDL-C concentrations during the experimental MedDiet. Apo A-2 concentrations demonstrated a sex $\times$ time interaction $(P=0.05)$, men having a more pronounced decrease than women in response to the MedDiet. There was no sex $\times$ time interaction for other variables related to lipid profile.

Table 3. Characteristics of men and women before the 4-week experimental Mediterranean diet (MedDiet) phase

(Mean values and standard deviations)

\begin{tabular}{|c|c|c|c|c|}
\hline & \multicolumn{2}{|c|}{ Men $(n 37)$} & \multicolumn{2}{|c|}{ Women (n 32) } \\
\hline & Mean & SD & Mean & SD \\
\hline Age (years) & $42 \cdot 6$ & $7 \cdot 3$ & $41 \cdot 2$ & $7 \cdot 3$ \\
\hline Body weight $(\mathrm{kg}) \dagger$ & 91.8 & $14 \cdot 0$ & $78.0^{*}$ & 14.7 \\
\hline BMI $\left(\mathrm{kg} / \mathrm{m}^{2}\right) \dagger$ & $29 \cdot 2$ & $3 \cdot 2$ & $29 \cdot 6$ & 5.4 \\
\hline $\begin{array}{l}\text { Waist circumference } \\
(\mathrm{cm}) \dagger\end{array}$ & $102 \cdot 6$ & $10 \cdot 7$ & $96 \cdot 4^{*}$ & $10 \cdot 5$ \\
\hline TAG $(\mathrm{mmol} / \mathrm{l}) \dagger$ & 1.86 & $1 \cdot 17$ & $1 \cdot 36^{\star}$ & 0.63 \\
\hline $\begin{array}{l}\text { Total cholesterol } \\
(\mathrm{mmol} / \mathrm{l})\end{array}$ & $5 \cdot 56$ & 0.91 & 5.40 & 0.60 \\
\hline LDL-C (mmol/l) & $3 \cdot 61$ & 0.72 & $3 \cdot 47$ & 0.52 \\
\hline $\mathrm{HDL}-\mathrm{C}(\mathrm{mmol} / \mathrm{l}) \dagger$ & 1.09 & 0.31 & $1 \cdot 30^{\star}$ & 0.26 \\
\hline ApoB $(g / l)$ & $1 \cdot 14$ & 0.22 & $1 \cdot 04^{*}$ & 0.14 \\
\hline ApoA-1 (g/l) & 1.32 & 0.20 & $1.42^{*}$ & 0.15 \\
\hline ApoA-2 $(g / l)$ & 0.35 & 0.06 & 0.34 & 0.05 \\
\hline $\begin{array}{l}\text { Systolic blood pressure } \\
\quad(\mathrm{mmHg})\end{array}$ & $117 \cdot 1$ & $12 \cdot 6$ & $108 \cdot 6^{*}$ & $10 \cdot 4$ \\
\hline $\begin{array}{l}\text { Diastolic blood pressure } \\
\quad(\mathrm{mmHg})\end{array}$ & $80 \cdot 3$ & $9 \cdot 0$ & $73 \cdot 5^{\star}$ & $9 \cdot 0$ \\
\hline $\begin{array}{l}\text { Fasting glucose } \\
(\mathrm{mmol} / \mathrm{l}) \dagger\end{array}$ & $5 \cdot 89$ & 0.37 & $5 \cdot 68^{\star}$ & 0.63 \\
\hline Glucose $2 \mathrm{~h}$ postload $(\mathrm{mmol} / \mathrm{l})$ & $6 \cdot 36$ & 1.81 & 7.02 & $2 \cdot 48$ \\
\hline $\begin{array}{l}\text { Fasting insulin } \\
(\mathrm{pmol} / \mathrm{l}) \dagger\end{array}$ & $96 \cdot 0$ & $57 \cdot 6$ & $86 \cdot 2$ & $79 \cdot 3$ \\
\hline Insulin $2 \mathrm{~h}$ postload $(\mathrm{pmol} / \mathrm{l}) \dagger$ & $493 \cdot 8$ & $443 \cdot 0$ & $520 \cdot 9$ & $588 \cdot 7$ \\
\hline HOMA index†‡ & 0.068 & 0.107 & $0 \cdot 101$ & $0 \cdot 162$ \\
\hline \multicolumn{5}{|c|}{$\begin{array}{l}\text { * Mean values were significantly different between groups before the experimental } \\
\text { MedDiet }(P<0.05 \text {, Student's } t \text { test). } \\
\dagger \text { Analysis was performed on transformed values. } \\
\text { †Calculated as }(1 / \text { (fasting glucose (mmol/l) } \times \text { fasting insulin (pmol/l/)/22.5)) for } \\
\text { measuring insulin sensitivity. }\end{array}$} \\
\hline
\end{tabular}

In regards to glucose and insulin concentrations, $2 \mathrm{~h}$ postload insulin concentrations demonstrated a sex $\times$ time interaction in response to the MedDiet ( $P=0.03$; Table 5$)$. In fact, $2 \mathrm{~h}$ postload insulin concentrations decreased in men, whereas women showed a non-significant decrease. There was no change for fasting glucose and insulin concentrations, $2 \mathrm{~h}$ postload glucose concentrations and for homeostasis model assessment index in both men and women in response to the MedDiet. After adjustments for the percentage of energy intake derived from alcohol intake at baseline, we obtained similar results for all metabolic variables.

\section{Discussion}

Results from this controlled-feeding study showed that adoption of the MedDiet leads to similar improvements in lipid profile and blood pressure in men and women. However, men and women responded differently for apoA-2 and $2 \mathrm{~h}$ postload insulin concentrations, since only men experienced significant decreases in response to the MedDiet. This is the first controlled study designed to compare the cardiovascular response of men and women to the MedDiet.

Previous controlled studies have observed that the response to alterations in dietary fat and carbohydrate intakes is smaller in women than in men for LDL-C and apoB ${ }^{(6)}$. Although the reduction in LDL-C in men $(-10 \cdot 4 \%)$ in our study was somewhat more important than in women $(-7 \cdot 3 \%)$, this difference was not significant. One reason that may explain this divergence between the literature and results that we actually obtained is that, contrary to previous controlled studies in which only one or a few nutrients were altered, the adoption of the MedDiet implies many dietary changes with complex combinations of nutrients. Thus, in addition to macronutrient intakes, other components of the MedDiet are likely to influence LDL-C and apoB changes such as fatty acids of the $\operatorname{diet}^{(7)}$ as well as phytosterol ${ }^{(23)}$ and soluble fibre ${ }^{(24)}$ intakes. Thus, men and women might not respond in the same manner to each individual nutrient of the MedDiet but overall, when considering the MedDiet as a whole, the resulting impacts on LDL-C and apoB are similar in men and women. These results are consistent with those of Estruch et al. ${ }^{(4)}$ who showed no sex differences for these variables in response to the adoption of the MedDiet in an uncontrolled context. However, in our study, we observed a more pronounced decrease in apoA-2 concentrations in men than in women. ApoA-2 is a lipoprotein linked to HDL-C and some evidence suggests that apoA-2 concentrations are negatively associated with the risk of $\mathrm{CHD}^{(25)}$. In our study, LDL-C:HDL-C ratio also decreased significantly in men, thereby suggesting that the decrease in apoA-2 in men in response to the MedDiet did not have, overall, a deleterious impact on the metabolism of plasma lipids and lipoproteins.

In our study, men and women responded differently for $2 \mathrm{~h}$ postload insulin concentrations, since only men experienced a significant decrease in response to the MedDiet. This is in line with results of the National Health and Nutrition Examination Survey III study which showed that the adherence to the MedDiet is positively associated with insulin sensitivity in men but 
Table 4. Dietary intakes of men and women before the 4-week experimental Mediterranean diet (MedDiet) phase

(Mean values and standard deviations)

\begin{tabular}{|c|c|c|c|c|}
\hline & \multicolumn{2}{|c|}{ Men $(n 37)$} & \multicolumn{2}{|c|}{ Women ( $n$ 32) } \\
\hline & Mean & SD & Mean & SD \\
\hline Energy $(\mathrm{kJ}) \dagger$ & 12402 & 3056 & $9492^{*}$ & 1994 \\
\hline Carbohydrate ( $\%$ of total energy) & $45 \cdot 2$ & 7.3 & $47 \cdot 5$ & $5 \cdot 6$ \\
\hline Protein (\% of total energy) & $17 \cdot 2$ & 3.2 & $17 \cdot 7$ & $2 \cdot 9$ \\
\hline Fat ( $\%$ of total energy)t & $34 \cdot 1$ & $5 \cdot 6$ & 33.2 & 6.4 \\
\hline SFA & $11 \cdot 0$ & 2.5 & $10 \cdot 6$ & $2 \cdot 3$ \\
\hline MUFAt & 14.5 & 3.0 & $14 \cdot 3$ & 4.8 \\
\hline PUFA† & $6 \cdot 0$ & 1.7 & 5.5 & 1.0 \\
\hline Alcohol ( $\%$ of total energy) $\dagger$ & 3.4 & 2.9 & $1.9^{*}$ & 1.9 \\
\hline MedScore (arbitrary units) & $24 \cdot 8$ & 5.9 & 24.6 & 4.4 \\
\hline MUFA:SFA ratio $†$ & 1.37 & 0.39 & 1.38 & 0.45 \\
\hline
\end{tabular}

MedScore, Mediterranean score

*Mean values were significantly different between men and women before the MedDiet $(P<0.05$, Student's $t$ test).

$\dagger$ Analysis was performed on transformed values.

not in pre-menopausal women ${ }^{(11)}$. One of the mechanisms that may explain this difference between men and women is adiponectin response to the MedDiet. Indeed, adiponectin has beneficial effects on insulin sensitivity ${ }^{(26)}$ and its concentration is influenced by sex hormone concentrations ${ }^{(26)}$ and dietary factors ${ }^{(27)}$. In fact, adoption of the MedDiet is associated with a higher adiponectin concentration ${ }^{(27)}$. Thus, it will be interesting in further studies to assess sex differences in adiponectin response to the MedDiet in order to perhaps shed some light on this sex difference in insulin homeostasis. women $^{*}$

(Changes, percentages of change, mean values with their standard errors)
Moreover, sex differences in body fat distribution may have also influenced the results observed for insulin homeostasis. Indeed, at every level of waist circumference, men have more visceral and less subcutaneous fat than do women ${ }^{(28)}$. Decreased visceral adipose tissue has significant metabolic consequences such as improvements in insulin sensitivity and in glucose tolerance ${ }^{(29)}$. Thus, even if waist circumference did not decrease significantly in both sexes in response to the MedDiet, it is possible that men have hydrolysed more visceral adipose tissue than women, leading to a greater improvement in insulin homeostasis. Although the visceral adipose tissue was not directly evaluated in our study, other studies will be needed in order to test this hypothesis. Finally, further studies are needed to investigate sex differences in response to the MedDiet on inflammatory and oxidative markers, since a decrease in these markers is associated with an improvement in insulin sensitivity ${ }^{(30)}$.

Some studies have shown that adoption of a MedDiet has a more cardioprotective effect in women than in $\operatorname{men}^{(9)}$. However, in our study, only men experienced a significant decrease in $2 \mathrm{~h}$ postload insulin concentration in response to the MedDiet. Moreover, HDL-C and TAG are stronger mediators of cardiovascular risk in women than in men ${ }^{(31)}$ and our results showed that these variables were unchanged in response to the MedDiet, which could be interpreted as limiting the beneficial effects of the MedDiet in women. Since some evidence suggests that women could benefit more from the MedDiet than men ${ }^{(9)}$, other studies are needed to assess the effects of the MedDiet on other cardiovascular

Table 5. Effects of the 4-week experimental Mediterranean diet on anthropometric and metabolic variables associated with CVD risk in men and

\begin{tabular}{|c|c|c|c|c|c|c|c|c|c|c|}
\hline \multirow[b]{2}{*}{ Variables } & \multicolumn{4}{|c|}{ Men ( $n$ 37) } & \multicolumn{4}{|c|}{ Women (n 32) } & \multicolumn{2}{|c|}{$\begin{array}{l}\text { Difference in } \\
\text { response between } \\
\text { sex }\end{array}$} \\
\hline & Change & SEM & $\Delta \%$ & $P$ & Change & SEM & $\Delta \%$ & $P$ & Mean & $P$ \\
\hline Body weight $(\mathrm{kg}) \dagger$ & $-1 \cdot 2$ & 0.2 & -1.3 & $<0.0001$ & -0.5 & 0.2 & -0.7 & 0.03 & -0.65 & 0.04 \\
\hline BMI $\left(\mathrm{kg} / \mathrm{m}^{2}\right) \dagger$ & -0.39 & 0.07 & -1.3 & $<0.0001$ & -0.20 & 0.06 & -0.7 & 0.06 & -0.18 & 0.04 \\
\hline Waist circumference $(\mathrm{cm}) \dagger$ & -0.29 & 0.44 & -0.3 & 0.94 & -0.80 & 0.45 & -0.8 & 0.30 & 0.51 & 0.37 \\
\hline $\mathrm{TAG}(\mathrm{mmol} / \mathrm{l}) \dagger$ & -0.27 & 0.14 & -14.6 & 0.25 & -0.11 & 0.08 & $-7 \cdot 7$ & 0.81 & -0.17 & 0.53 \\
\hline Total cholesterol $(\mathrm{mmol} / \mathrm{l})$ & -0.55 & 0.11 & -9.9 & $<0.0001$ & -0.33 & 0.10 & $-6 \cdot 2$ & 0.02 & -0.21 & 0.16 \\
\hline LDL-C (mmol/l) & -0.37 & 0.09 & $-10 \cdot 4$ & 0.003 & -0.25 & 0.09 & $-7 \cdot 3$ & 0.04 & -0.12 & 0.34 \\
\hline $\mathrm{HDL}-\mathrm{C}(\mathrm{mmol} / \mathrm{l}) \dagger$ & -0.05 & 0.02 & -4.4 & 0.13 & -0.03 & 0.02 & $-2 \cdot 6$ & 0.58 & -0.01 & 0.57 \\
\hline Total cholesterol:HDL-C ratio & -0.32 & 0.11 & $-6 \cdot 1$ & 0.01 & -0.18 & 0.10 & $-4 \cdot 3$ & 0.34 & -0.14 & 0.35 \\
\hline LDL-C:HDL-C ratio & -0.27 & 0.08 & $-7 \cdot 8$ & 0.007 & -0.13 & 0.08 & -4.6 & 0.46 & -0.14 & 0.24 \\
\hline ApoB $(g / l)$ & -0.11 & 0.03 & -9.5 & 0.0003 & -0.09 & 0.03 & $-9 \cdot 0$ & 0.005 & -0.01 & 0.69 \\
\hline ApoA-1 (g/l) & -0.08 & 0.02 & -5.9 & 0.0002 & -0.05 & 0.02 & -3.6 & 0.04 & -0.03 & 0.32 \\
\hline ApoA-2 (g/l) & -0.03 & 0.01 & -7.8 & $<0.0001$ & -0.01 & 0.00 & -3.7 & 0.11 & -0.015 & 0.047 \\
\hline Systolic blood pressure (mmHg) & -3.9 & 1.3 & -3.3 & 0.02 & $-3 \cdot 1$ & 1.2 & $-2 \cdot 8$ & $0 \cdot 10$ & -0.80 & 0.69 \\
\hline Diastolic blood pressure $(\mathrm{mmHg})$ & -3.6 & $1 \cdot 1$ & -4.5 & 0.003 & $-3 \cdot 2$ & 0.9 & $-4 \cdot 3$ & 0.01 & -0.39 & 0.82 \\
\hline Fasting glucose $(\mathrm{mmol} / \mathrm{l}) \dagger$ & 0.02 & 0.07 & 0.3 & 0.99 & -0.07 & 0.08 & $-1 \cdot 3$ & 0.88 & 0.09 & 0.47 \\
\hline $2 \mathrm{~h}$ postload glucose $(\mathrm{mmol} / \mathrm{l})$ & -0.55 & 0.27 & -8.7 & 0.14 & -0.29 & 0.25 & $-4 \cdot 1$ & 0.71 & -0.26 & 0.48 \\
\hline Fasting insulin $(\mathrm{pmol} / \mathrm{l}) \dagger$ & $-10 \cdot 0$ & 4.1 & -10.5 & 0.80 & $-6 \cdot 3$ & $7 \cdot 6$ & $-7 \cdot 3$ & 1.00 & $-3 \cdot 8$ & 0.56 \\
\hline $2 \mathrm{~h}$ postload insulin $(\mathrm{pmol} / \mathrm{l}) \dagger$ & $-125 \cdot 2$ & $58 \cdot 8$ & $-25 \cdot 4$ & 0.03 & $-53 \cdot 4$ & $57 \cdot 1$ & $-10 \cdot 3$ & 0.99 & $-71 \cdot 8$ & 0.03 \\
\hline HOMA index†‡ & -0.009 & 0.015 & $-12 \cdot 9$ & 0.88 & -0.018 & 0.020 & $-18 \cdot 0$ & 1.00 & 0.009 & 0.68 \\
\hline
\end{tabular}

$\Delta \%$, percentage of change; LDL-C, LDL-cholesterol; HDL-C, HDL-cholesterol; HOMA index, homeostasis model assessment index.

*All analyses for metabolic variables are adjusted for weight change during the experimental diet.

$\dagger$ Analysis was performed on transformed values.

$\ddagger$ Calculated as $(1 /$ (fasting glucose $(\mathrm{mmol} / \mathrm{l}) \times$ fasting insulin $(\mathrm{pmol} / \mathrm{l} / \mathrm{/22} \cdot 5)$ ) for measuring insulin sensitivity. 
markers such as inflammatory and endothelial function markers in order to have a more global assessment of the cardiovascular risk in both sexes.

One of the strengths of our study is a parallel design which permitted us to precisely evaluate sex differences in response to the MedDiet. This design allowed us to demonstrate for the first time that men and women do not seem to have exactly the same cardiovascular benefits in response to the MedDiet, a food pattern now widely recommended for its cardioprotective effects. Moreover, our results also showed that the cardioprotective effects of the MedDiet were observed above those of the Canada's Food Guide recommendations. However, one limitation is that the study's 'single strand before and after' design does not allow comparisons to a control diet, which limits the conclusions on true treatment effects. However, since the cardioprotective effects of the MedDiet are well known and have been widely documented $^{(32)}$, this study had as a main objective to investigate sex-related differences in response to the MedDiet, which was possible since baseline dietary intakes were similar between both sexes before the controlled intervention, facilitating the comparison between men and women. Another limitation of our study is that control over food intake cannot be perfect since participants consumed two meals per day out of the Clinical Investigation Unit. However, this limitation was overcome by providing all foods and drinks to participants and by daily visit at our Institute. The short duration of the study may also be considered as a limitation. However, it has been shown in the literature that 4 weeks of nutritional intervention under controlled conditions is sufficient to obtain significant changes in cardiometabolic variables in men and premenopausal women ${ }^{(33-35)}$. Moreover, it has even been observed that after 2 weeks of feeding, changes in many metabolic variables were already maximised ${ }^{(36)}$. Finally, since women in different hormonal phases could have different effects from the dietary intervention, this limits the inference of the observed results. However, the challenge imposed by the hormonal cycle in premenopausal women has as consequence that very few studies have done controlled dietary intervention in premenopausal women, resulting in a very scarce literature. For this reason, the inclusion of premenopausal women in this study brings some new and relevant results in the literature.

In summary, consuming a traditional MedDiet leads to beneficial changes in plasma lipid profile and blood pressure in both men and women at moderate risk of CVD. However, in our cohort, results showed that the MedDiet seems to lead to significant improvements in insulin homeostasis in men but not in women. Clinically, these results highlight the fact that cardiovascular differences may exist between men and women in response to the MedDiet and further studies are needed to acquire a better understanding of sex differences in response to diet, which may be useful in order to provide perhaps sex-specific nutritional strategies in the prevention of CVD.

\section{Acknowledgements}

The present research was supported by the Canadian Institutes of Health Research (MOP 84568) and the Heart and Stroke Foundation of Quebec (2007-180). Funding sources had no involvement in the study design, in the collection, analysis and interpretation of data, in the writing of the report and in the decision to submit the paper for publication. A. B. is a recipient of a studentship from Canadian Institutes of Health Research (CIHR). The authors' contributions to this study were as follows: S. L. designed the research; A. B., M. R. and L. C. conducted the research; S. D.supervised the medical condition of the participants; A. B. analysed the data and wrote the paper; A. B. and S. L. had primary responsibility for the final content; all the authors revised, read and approved the final manuscript. The authors report no conflicts of interest related to the present study.

\section{References}

1. Canadian Cancer Society's Steering Committee (2010) Canadian Cancer Statistics 2010. Toronto: Canadian Cancer Society.

2. Keys A (1970) Coronary heart disease in seven countries. Circulation 41, I1-I211.

3. Panagiotakos DB, Tzima N, Pitsavos C, et al. (2007) The association between adherence to the Mediterranean diet and fasting indices of glucose homoeostasis: the ATTICA Study. J Am Coll Nutr 26, 32-38.

4. Estruch R, Martinez-Gonzalez MA, Corella D, et al. (2006) Effects of a Mediterranean-style diet on cardiovascular risk factors: a randomized trial. Ann Intern Med 145, 1-11.

5. Panagiotakos DB, Pitsavos C, Polychronopoulos E, et al. (2004) Can a Mediterranean diet moderate the development and clinical progression of coronary heart disease? A systematic review. Med Sci Monit 10, RA193-RA198.

6. Knopp RH, Paramsothy P, Retzlaff BM, et al. (2005) Gender differences in lipoprotein metabolism and dietary response: basis in hormonal differences and implications for cardiovascular disease. Curr Atheroscler Rep 7, 472-479.

7. Lapointe A, Balk EM \& Lichtenstein AH (2006) Gender differences in plasma lipid response to dietary fat. Nutr Rev $\mathbf{6 4}$, 234-249.

8. World Health Organization Study Group (2003) Diet, Nutrition, and the Prevention of Chronic Diseases. WHO Technical Report Series no. 916. Geneva: WHO.

9. Chrysohoou C, Panagiotakos DB, Pitsavos C, et al. (2003) Gender differences on the risk evaluation of acute coronary syndromes: the CARDIO2000 study. Prev Cardiol 6, 71-77.

10. Mennen LI, Sapinho D, de Bree A, et al. (2004) Consumption of foods rich in flavonoids is related to a decreased cardiovascular risk in apparently healthy French women. $J$ Nutr 134, 923-926.

11. Carter SJ, Roberts MB, Salter J, et al. (2010) Relationship between Mediterranean Diet Score and atherothrombotic risk: findings from the Third National Health and Nutrition Examination Survey (NHANES III), 1988-1994. Atherosclerosis 210, 630-636.

12. National Cholesterol Education Program (NCEP) Expert Panel (2002) Third Report of the National Cholesterol Education Program (NCEP) Expert Panel on Detection, Evaluation, and Treatment of High Blood Cholesterol in Adults (Adult Treatment Panel III) final report. Circulation 106 , 3143-3421. 
13. International Diabetes Federation (2006) IDF worldwide definition of the metabolic syndrome. http://www.idf.org/ webdata/docs/IDF_Meta_def_final.pdf (accessed July 2011).

14. Minister of Health Canada (2007) Eating well with Canada's Food Guide. http://www.hc-sc.gc.ca/fn-an/alt_formats/hpfbdgpsa/pdf/food-guide-aliment/view_eatwell_vue_bienmangeng.pdf (accessed July 2011).

15. Willett WC, Sacks F, Trichopoulou A, et al. (1995) Mediterranean diet pyramid: a cultural model for healthy eating. Am J Clin Nutr 61, 1402S-1406S.

16. Saura-Calixto F \& Goni I (2009) Definition of the Mediterranean diet based on bioactive compounds. Crit Rev Food Sci Nutr 49, 145-152.

17. Goulet J, Nadeau G, Lapointe A, et al. (2004) Validity and reproducibility of an interviewer-administered food frequency questionnaire for healthy French-Canadian men and women. Nutr J 3, 13.

18. Muesing RA, Forman MR, Graubard BI, et al. (1996) Cyclic changes in lipoprotein and apolipoprotein levels during the menstrual cycle in healthy premenopausal women on a controlled diet. J Clin Endocrinol Metab 81, 3599-3603.

19. Goulet J, Lamarche B, Nadeau G, et al. (2003) Effect of a nutritional intervention promoting the Mediterranean food pattern on plasma lipids, lipoproteins and body weight in healthy French-Canadian women. Atherosclerosis 170, 115-124

20. Richterich R \& Dauwalder H (1971) Determination of plasma glucose by hexokinase-glucose-6-phosphate dehydrogenase method. Schweiz Med Wochenschr 101, 615-618.

21. Desbuquois B \& Aurbach GD (1971) Use of polyethylene glycol to separate free and antibody-bound peptide hormones in radioimmunoassays. J Clin Endocrinol Metab 33, $732-738$

22. Lohman T, Roche A \& Martorell R (1988) The Airlie (VA) consensus conference. In Anthropometric Standardization Reference Manual [TG Lohman, AF Roche and R Martorell, editors]. Champaign, IL: Human Kinetics.

23. Neil HA, Meijer GW \& Roe LS (2001) Randomised controlled trial of use by hypercholesterolaemic patients of a vegetable oil sterol-enriched fat spread. Atherosclerosis 156, 329-337.
24. Erkkila AT \& Lichtenstein AH (2006) Fiber and cardiovascular disease risk: how strong is the evidence? J Cardiovasc Nurs 21, 3-8

25. Birjmohun RS, Dallinga-Thie GM, Kuivenhoven JA, et al. (2007) Apolipoprotein A-II is inversely associated with risk of future coronary artery disease. Circulation 116, 2029-2035.

26. Swarbrick MM \& Havel PJ (2008) Physiological, pharmacological, and nutritional regulation of circulating adiponectin concentrations in humans. Metab Syndr Relat Disord 6, 87-102.

27. Fragopoulou E, Panagiotakos DB, Pitsavos C, et al. (2010) The association between adherence to the Mediterranean diet and adiponectin levels among healthy adults: the ATTICA study. J Nutr Biochem 21, 285-289.

28. Sumner AE (2008) The relationship of body fat to metabolic disease: influence of sex and ethnicity. Gend Med 5, 361-371.

29. Despres JP \& Lemieux I (2006) Abdominal obesity and metabolic syndrome. Nature 444, 881-887.

30. Schroder H (2007) Protective mechanisms of the Mediterranean diet in obesity and type 2 diabetes. $J$ Nutr Biochem 18, 149-160.

31. Meagher EA (2004) Addressing cardiovascular disease in women: focus on dyslipidemia. J Am Board Fam Pract 17, 424-437.

32. Lairon D (2007) Intervention studies on Mediterranean diet and cardiovascular risk. Mol Nutr Food Res 51, 1209-1214.

33. Beauchesne-Rondeau E, Gascon A, Bergeron J, et al. (2003) Plasma lipids and lipoproteins in hypercholesterolemic men fed a lipid-lowering diet containing lean beef, lean fish, or poultry. Am J Clin Nutr 77, 587-593

34. Chisholm A, Mann J, Skeaff M, et al. (1998) A diet rich in walnuts favourably influences plasma fatty acid profile in moderately hyperlipidaemic subjects. Eur J Clin Nutr 52, 12-16.

35. Gerhard GT, Connor SL, Wander RC, et al. (2000) Plasma lipid and lipoprotein responsiveness to dietary fat and cholesterol in premenopausal African American and white women. Am J Clin Nutr 72, 56-63.

36. Hodson L, Skeaff CM \& McKenzie JE (2002) Maximal response to a plasma cholesterol-lowering diet is achieved within two weeks. Nutr Metab Cardiovasc Dis 12, 291-295. 